\title{
Density Functional Theory Calculations for the Evaluation of FePS 3 as a Promising Anode for Mg lon Batteries
}

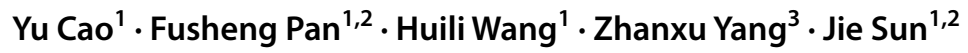

Received: 25 March 2020 / Revised: 5 April 2020 / Accepted: 9 April 2020 / Published online: 7 May 2020

(c) The Author(s) 2020

\begin{abstract}
$\mathrm{FePS}_{3}$, a classical 2D layered material with transition metal phosphorous trichalcogenides, was investigated as an anode material for $\mathrm{Mg}$ ion batteries. We used density functional theory to calculate the $\mathrm{Mg}$ storage properties of $\mathrm{FePS}_{3}$, such as $\mathrm{Mg}$ adsorption energy, theoretical specific capacity, average voltage, diffusion energy barriers, volume change, and electronic conductivity. The theoretical specific capacity of the $\mathrm{FePS}_{3}$ monolayer is $585.6 \mathrm{~mA} \mathrm{~h} / \mathrm{g}$ with a relatively low average voltage of $0.483 \mathrm{~V}$ (vs. $\mathrm{Mg} / \mathrm{Mg}^{2+}$ ), which is favorable to a high energy density. The slight change in volume and good electronic conductivity of bulk $\mathrm{FePS}_{3}$ are beneficial to electrode stability during cycling.
\end{abstract}

Keywords $\mathrm{Mg}$ ion battery $\cdot \mathrm{FePS}_{3} \cdot$ Density functional theory $\cdot$ Anode material

\section{Introduction}

The growing demand for energy sources results in the excessive consumption of limited and nonrenewable fossil fuels, and consequential environmental problems have become increasingly prominent. To address this urgent issue, researchers focused on renewable energies and efficient energy storage systems [1,2]. As one of the most successful technology for energy storage, rechargeable lithium-ion batteries (LIBs) have been widely applied to scalable energy storage systems, electric vehicles, and portable electronic

Electronic supplementary material The online version of this article (https://doi.org/10.1007/s12209-020-00253-9) contains supplementary material, which is available to authorized users.

Zhanxu Yang

yangzhanxu@lnpu.edu.cn

$\triangle$ Jie Sun

jies@tju.edu.cn

1 Key Laboratory for Green Chemical Technology of Ministry of Education, School of Chemical Engineering and Technology, Tianjin University, Tianjin 300072, China

2 State Key Laboratory of Organic-Inorganic Composites, Beijing University of Chemical Technology, Beijing 100029, China

3 College of Chemistry, Chemical Engineering and Environment Engineering, Liaoning Shihua University, Fushun 113001, China devices [3-5]. Although LIBs have become advanced and widely available rechargeable batteries, they have not been regarded as ideal sustainable sources of energy storage equipment because of the scarcity, high cost, and safety problems of lithium [6, 7]. Magnesium-ion batteries (MIBs) have attracted increasing attention because of their low cost, safety, and natural abundance. The price of $\mathrm{Mg}(35 \$ / \mathrm{kg})$ is lower than that of $\mathrm{Li}(1500 \$ / \mathrm{kg})$, and $\mathrm{Mg}$ reserves in the crust $(2.33 \%)$ are around 350 times larger than $\mathrm{Li}(0.0065 \%)$ [8]. In addition, MIBs exhibit more advantages in the electrochemical process $[9,10]$. First, the theoretical volumetric capacity of magnesium $\left(3832 \mathrm{~mA} \mathrm{~h} / \mathrm{cm}^{3}\right)$ is higher than that of lithium $\left(2062 \mathrm{~mA} \mathrm{~h} / \mathrm{cm}^{3}\right)$ [11] because of the divalent nature of $\mathrm{Mg}$ ion. Second, dendrite is a serious problem for lithium metal anodes, whereas magnesium metal used as an anode can achieve a dendrite-free deposition during cycling, resulting in a relatively safe cycling process [12]. As such, MIBs have been suggested as possible alternatives to battery technology. However, the reaction of $\mathrm{Mg}$ metal with electrolyte species causes an unstable solid electrolyte interface (SEI) and constant electrolyte consumption. Sluggish $\mathrm{Mg}$ ion diffusion in host materials due to the divalent nature of the $\mathrm{Mg}$ ion results in slow insertion/extraction reaction kinetics [13, 14].

Many efforts have been devoted to developing cathode materials, such as $\mathrm{Mo}_{6} \mathrm{~S}_{8}$ [15], $\mathrm{TiS}_{2}$ [16], and $\mathrm{V}_{2} \mathrm{O}_{5}$ [17], but a few works have designed anode materials, such as $\mathrm{Ga}$ [18], Sn [19], and Bi [20, 21], to replace Mg metal. 
$\mathrm{Mo}_{6} \mathrm{~S}_{8}$ is one of the best cathode materials because of its good electrochemical performance and compatibility with electrolytes, but the cycling performance of MIBs remains poor because of the anode side of $\mathrm{Mg}$ metal, such as the large volume change during the discharge/charge process and sluggish $\mathrm{Mg}$ ion diffusion in a dense SEI layer [22]. To our knowledge, the use of layered materials in LIBs can significantly buffer the change in volume and promote Li-ion transfer in an interlayer space [23,24], and this strategy can be used in MIBs. For example, layered $\mathrm{Na}_{2} \mathrm{Ti}_{3} \mathrm{O}_{7}$ nanoribbons exhibit an actual reversible capacity of $78 \mathrm{~mA} \mathrm{~h} / \mathrm{g}$ at $20 \mathrm{~mA} / \mathrm{g}$ after 100 cycles [25]. Luo et al. [26] reported that layered $\mathrm{Na}_{2} \mathrm{Ti}_{6} \mathrm{O}_{13}$ nanowires display a stable capacity of $51.2 \mathrm{~mA} \mathrm{~h} / \mathrm{g}$ at $100 \mathrm{~mA} / \mathrm{g}$ after 300 cycles. Many theoretical calculations have verified that layered materials, such as arsenene [27], $\mathrm{MnSb}_{2} \mathrm{~S}_{4}$ [28], MXene [29], phosphorene [8], $\mathrm{WS}_{2}$ [30], and $\mathrm{C}_{3} \mathrm{~N}_{4}$ [31], can be promising anode materials for MIBs. Furthermore, 2D layered transition metal phosphorous trichalcogenides $\left(M \mathrm{P} X_{3}\right.$, where $M=\mathrm{Mn}, \mathrm{Fe}$, $\mathrm{Ni}$, etc., and $X=\mathrm{S}, \mathrm{Se}$ ) have been widely explored because of their interesting physicochemical features, including electronic, magnetic, and superconductive properties [32, 33]. Hitherto, materials from the $M \mathrm{P} X_{3}$ family serve as good candidates for LIBs because of their reversible lithium storage capacity and fast lithium ion/electron conduction [34-36]. However, no study has explored the magnesium storage capacity of $M \mathrm{P} X_{3}$ materials.

In this work, theoretical studies on $\mathrm{FePS}_{3}$ anode for MIB application were presented. FePS ${ }_{3}$, a classical $M P X_{3}$ material, is expected to be a promising anode for MIBs because of its large specific surface area, abundant active sites, and fast ion diffusion. $\mathrm{FePS}_{3}$ has a moderate electronic conductivity of $10^{-5} \mathrm{~S} / \mathrm{cm}$, which is significantly higher than that of other $M \mathrm{PX} X_{3}$ materials, such as $\mathrm{MnPS}_{3}, \mathrm{NiPS}_{3}$, and $\mathrm{ZnPS}_{3}$ (around $10^{-9} \mathrm{~S} / \mathrm{cm}$ ). Herein, density functional theory (DFT) calculations were conducted to analyze $\mathrm{Mg}$ adsorption and diffusion properties in an $\mathrm{FePS}_{3}$ monolayer, and the volume change and electronic conductivity of the bulk $\mathrm{FePS}_{3}$ for its potential applications as an anode candidate for MIBs.

\section{Computational Details}

All calculations were carried out using the Cambridge Sequential Total Energy (CASTEP) package within the DFT framework in the Materials Studio Version 5.5. Generalized gradient approximation with Perdew-Burke-Ernzerhof functional (GGA-PBE) was used for the exchange correlation energy. An ultrasoft pseudopotential was used and the energy tolerance in the self-consistent field (SCF) calculations was $2 \times 10^{-6} \mathrm{eV} /$ atom. The convergence conditions were set as $2 \times 10^{-5} \mathrm{eV} /$ atom for the energy change, $0.05 \mathrm{eV} / \AA$ for the force change, $2 \times 10^{-3} \AA$ for the atomic displacement and $0.05 \AA^{-1}$ for the K-point separations. The structure was relaxed using $4 \times 4 \times 1$ (monolayer $\mathrm{FePS}_{3}$ ) and $4 \times 4 \times 3$ (bulk $\mathrm{FePS}_{3}$ ) K-point meshes.

\section{Results and Discussion}

\section{Adsorption of $\mathrm{Mg}$ on an $\mathrm{FePS}_{3}$ Monolayer}

The relaxed structure of the $\mathrm{FePS}_{3}$ monolayer is displayed in Fig. 1a, b. Similar to other $M \mathrm{P} X_{3}$ materials, $\mathrm{FePS}_{3}$ shows a sandwich structure with $\mathrm{Fe}$ atoms in the middle of monolayer. Each $\mathrm{Fe}$ atom bonds with three $\mathrm{S}$ atoms on the upper side of the $\mathrm{FePS}_{3}$ monolayer and three $\mathrm{S}$ atoms on the lower side. Each $\mathrm{P}$ atom bonds with three $\mathrm{S}$ atoms and another $\mathrm{P}$ atom. Each $\mathrm{S}$ atom is situated in the same chemical environment with two S-Fe bonds and one S-P bond. The lengths of S-Fe, S-P, and P-P bonds are about 2.520, 2.045, and $2.195 \AA$, respectively. The lattice constants of the primitive $\mathrm{FePS}_{3}$ cell is $a=b=5.932 \AA$. A $2 \times 2$ supercell was used to explore the adsorption properties of the $\mathrm{FePS}_{3}$ monolayer. A $\mathrm{Mg}$ atom was initially placed at different sites on the surface of the $\mathrm{FePS}_{3}$ monolayer with a certain distance of $1.50 \AA$. Figure 1a shows the possible sites at $\mathrm{Fe}, \mathrm{P}$, and $\mathrm{S}$ atoms and a hollow position, which are denoted as $\mathrm{Fe}, \mathrm{P}, \mathrm{S}$, and $\mathrm{H}$ sites, respectively. Figure 1c illustrates the structures of the $\mathrm{FePS}_{3}$ monolayer loaded with a $\mathrm{Mg}$ atom before and after geometric optimization. $\mathrm{Mg}$ adsorbed at $\mathrm{S}$ and $\mathrm{H}$ sites moves to the same position after structure relaxation. Adsorption energy $\left(E_{\text {ads }}\right)$ was calculated with the following expression to find the most stable structure of the $\mathrm{FePS}_{3}$ monolayer loaded with $\mathrm{Mg}$ :

$E_{\text {ads }}=E_{\text {total }}-E_{\mathrm{FePS}_{3}}-E_{\mathrm{Mg}}$

where $E_{\mathrm{FePS} 3}$ and $E_{\text {total }}$ represent the energy of the $\mathrm{FePS}_{3}$ monolayer before and after loading $\mathrm{Mg}$, respectively, and $E_{\mathrm{Mg}}$ is the energy of single $\mathrm{Mg}$ atom. In Table 1, the largest adsorption energy $(-4.45 \mathrm{eV})$ occurs at the Fe site, and the second stable adsorption energy $(-4.39 \mathrm{eV})$ corresponds to the $\mathrm{H}$ site. The spatial distribution of the difference in the charge density of the $\mathrm{FePS}_{3}$ monolayer (Fig. 1d) was used to explain the reason for the most stable structure of $\mathrm{Mg}$ adsorbed at the $\mathrm{Fe}$ site. Blue and yellow correspond to electron-accumulated and electron-depleted regions, respectively. Obviously, the electron-accumulated regions are at $\mathrm{S}$ atoms around $\mathrm{Fe}$ sites, which are beneficial to $\mathrm{Mg}$ loading. Therefore, the most stable structure is $\mathrm{Mg}$ adsorbed at the $\mathrm{Fe}$ site with three $\mathrm{Mg}-\mathrm{S}$ bonds. The distances between $\mathrm{Mg}$ and adjacent $S$ atoms are summarized in Table 1. The smallest distances of $\mathrm{Mg}$ atom with surrounded $\mathrm{S}$ atoms are at the $\mathrm{Fe}$ site, further indicating that the most stable structure is $\mathrm{Mg}$ adsorbed at the $\mathrm{Fe}$ site. The charge density difference slice 
a
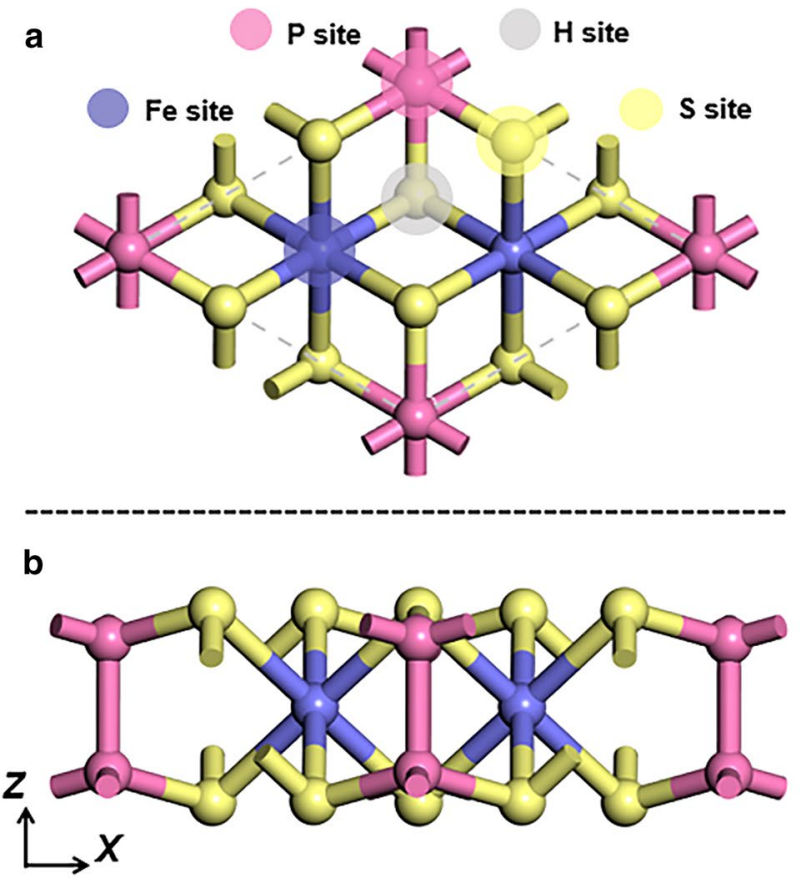

C
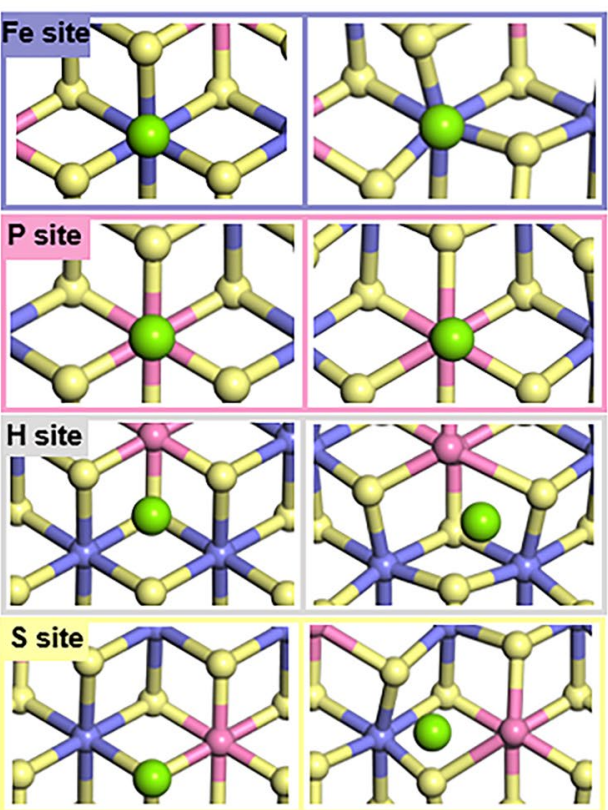

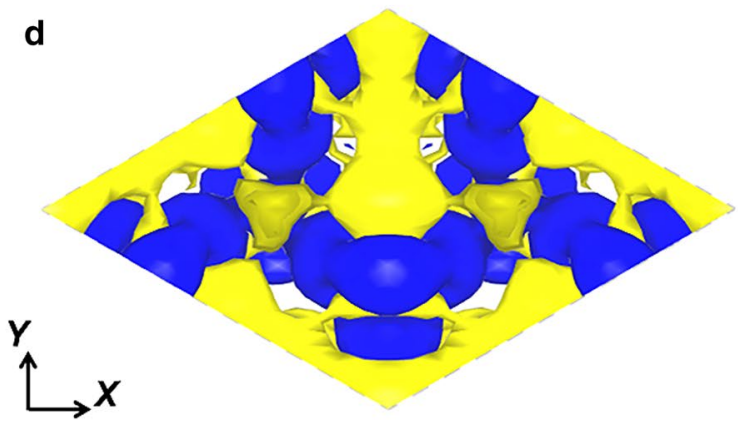

d

Fig. 1 a Top and $\mathbf{b}$ side views of the optimized structures of the $\mathrm{FePS}_{3}$ monolayer and the possible sites for $\mathrm{Mg}$ adsorption, c Structures of the $\mathrm{FePS}_{3}$ monolayer with $\mathrm{Mg}$ loaded at different sites before (left) and after structure relaxation (right), d Spatial distribution of

Table 1 Data of adsorption energy $\left(E_{\text {ads }}\right)$, Mulliken charge, and distances between $\mathrm{Mg}$ and adjacent $\mathrm{S}$ at four possible adsorption sites in the $\mathrm{FePS}_{3}$ monolayer

\begin{tabular}{llllll}
\hline Adsorption site & $E_{\text {ads }}(\mathrm{eV})$ & $\begin{array}{l}\text { Mulliken } \\
\text { charge }(|e|)\end{array}$ & \multicolumn{2}{l}{$\begin{array}{l}\text { Distance between } \mathrm{Mg} \\
\text { and adjacent S }(\AA)\end{array}$} \\
\hline Fe site & -4.45 & 1.08 & 2.425 & 2.394 & 2.363 \\
P site & -3.68 & 0.54 & 3.473 & 3.419 & 3.280 \\
H site & -4.39 & 0.88 & 3.374 & 2.515 & 2.484 \\
S site & -4.33 & 0.87 & 3.599 & 2.578 & 2.462 \\
\hline
\end{tabular}

map (Fig. 1e) was used to explore the nature of the $\mathrm{Mg}-\mathrm{S}$ bond. Electrons tend to move close to $\mathrm{S}$, indicating that the $\mathrm{Mg}-\mathrm{S}$ bond approaches a polar ionic bond. The Mulliken charge of $\mathrm{Mg}$ (Table 1) was calculated to confirm the charge transfer from $\mathrm{S}$ to $\mathrm{Mg}$. The Mulliken charge value of $\mathrm{Mg}$ at

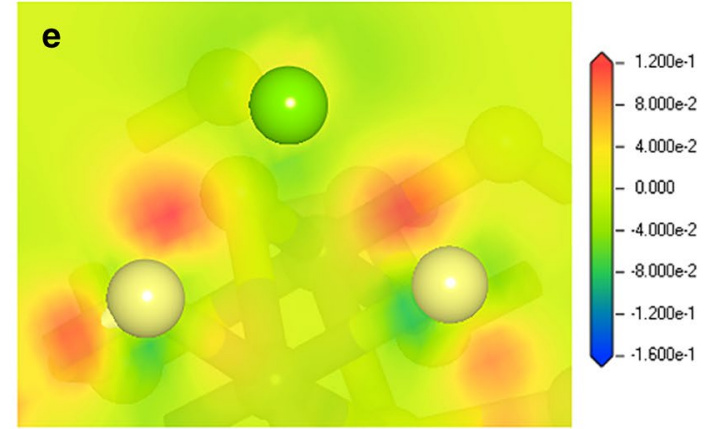

charge density difference of the $\mathrm{FePS}_{3}$ monolayer, e The charge density difference slice map of the $\mathrm{FePS}_{3}$ monolayer absorbed with $\mathrm{Mg}$. Blue, yellow, pink, and green balls represent Fe, S, P, and Mg atoms, respectively

the Fe site is 1.08 lel, which is apparently larger than that of other sites, proving that more charge transfers occur. In summary, $\mathrm{Mg}$ prefers to be adsorbed at the Fe site of the $\mathrm{FePS}_{3}$ monolayer to form the most stable structure.

\section{Theoretical Specific Capacity and Voltage Profile of the $\mathrm{FePS}_{3}$ Monolayer}

In $\mathrm{Mg}_{x} \mathrm{FePS}_{3}, x$ represents the concentration of $\mathrm{Mg}$ in the $\mathrm{FePS}_{3}$ monolayer. The optimized structures of $\mathrm{Mg}_{x} \mathrm{FePS}$ with different $x$ values are depicted in Fig. $2 \mathrm{a}$. Mg atoms are initially placed at $\mathrm{Fe}$ sites on one side of the $\mathrm{FePS}_{3}$ monolayer by using a $2 \times 2$ supercell. Obviously, all the Fe sites on one side are successfully occupied with eight $\mathrm{Mg}$ atoms corresponding to the formula of $\mathrm{MgFePS}_{3}$. Afterward, the meta-stable $\mathrm{H}$ sites on the same side are also 


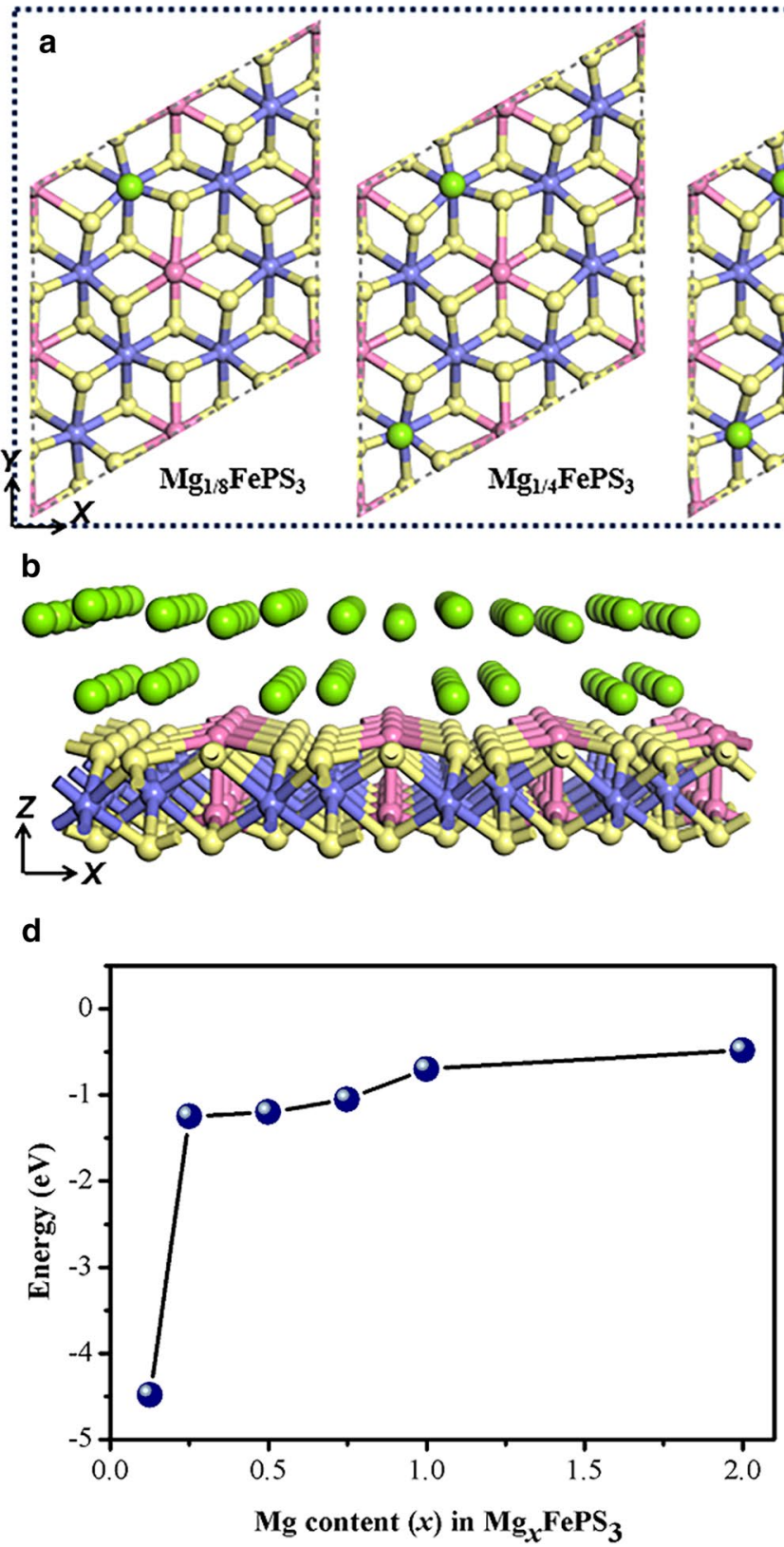

Fig. 2 a Configurations of the schematic of $\mathrm{Mg}_{x} \mathrm{FePS}_{3}$ with $\mathrm{Mg}$ adsorbed on one side of the $\mathrm{FePS}_{3}$ monolayer $(x=1 / 8 \sim 1)$; b Optimized structure of the $\mathrm{FePS}_{3}$ monolayer with $\mathrm{Mg}$ adsorbed on both $\mathrm{Fe}$ and $\mathrm{H}$ sites on the same side; $\mathbf{c}$ Configurations of the schematic of

considered to load $\mathrm{Mg}$ after the Fe sites are fully occupied. However, the $\mathrm{Mg}$ atoms cannot be embedded at the $\mathrm{H}$ sites because all $\mathrm{Mg}$ atoms at $\mathrm{H}$ sites are extruded out of the $\mathrm{FePS}_{3}$ surface after structure relaxation (Fig. 2b). $\mathrm{Mg}$ storage on the double sides of the $\mathrm{FePS}_{3}$ monolayer was calculated on the basis of the basic structure $\left(\mathrm{MgFePS}_{3}\right)$ in which $\mathrm{Fe}$ sites were fully occupied with $\mathrm{Mg}$ atoms on one side to obtain the maximum capacity. On the other side, both $\mathrm{H}$ sites and Fe sites can absorb $\mathrm{Mg}$
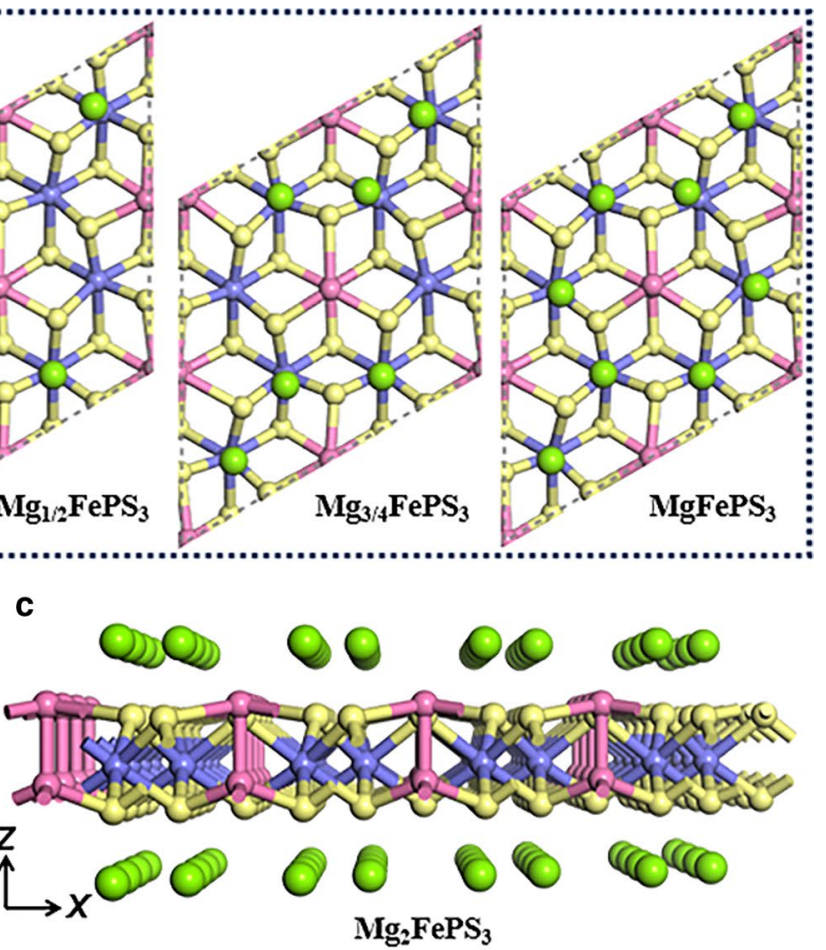

e

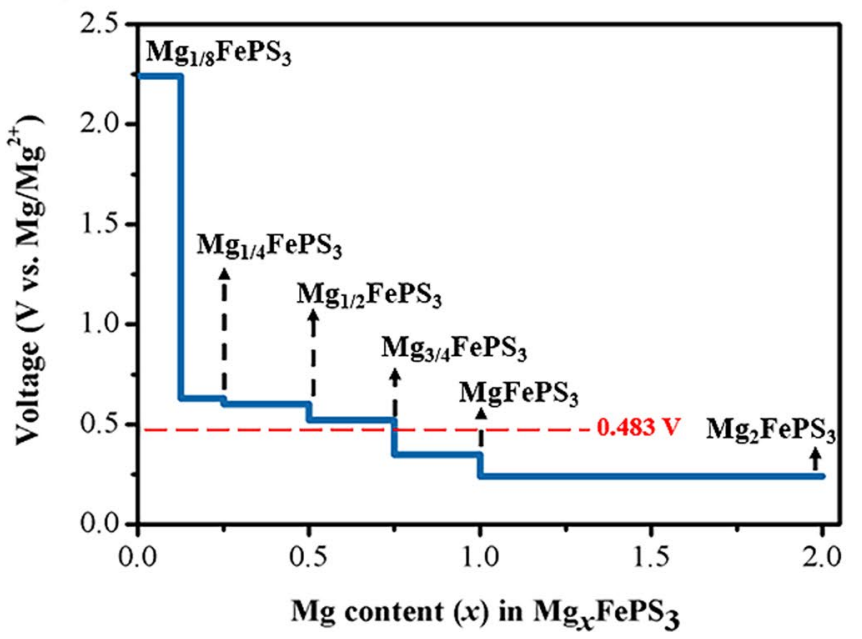

$\mathrm{Mg}_{2} \mathrm{FePS}_{3}$ with $\mathrm{Mg}$ adsorbed on both sides of the $\mathrm{FePS}_{3}$ monolayer; d Adsorption energies with respect to $\mathrm{Mg}$ concentration; e Voltage profile with respect to $\mathrm{Mg}$ content from 0 to 2

ion. In Fig. S1, the structure of the $\mathrm{FePS}_{3}$ monolayer irreversibly deforms when the $\mathrm{H}$ sites are fully occupied with $\mathrm{Mg}$, indicating thermodynamic instability. By contrast, the structure of the $\mathrm{FePS}_{3}$ monolayer slightly changes when the Fe sites on both sides are fully occupied with $\mathrm{Mg}$. This result indicates a stable structure, corresponding to the formula of $\mathrm{Mg}_{2} \mathrm{FePS}_{3}$ (Figs. 2c and S1). Figure $2 \mathrm{~d}$ shows the adsorption energies of $\mathrm{Mg}_{x} \mathrm{FePS}_{3}$ with an increasing absolute $x$ (from $1 / 8$ to 2). Obviously, the 
absolute value of adsorption energy gradually decreases as $\mathrm{Mg}$ concentration increases due to repulsive interactions between adjacent $\mathrm{Mg}$ cations. As a consequence, the maximum $\mathrm{Mg}$ concentration in the $\mathrm{FePS}_{3}$ monolayer corresponds to the formula of $\mathrm{Mg}_{2} \mathrm{FePS}_{3}$ with a theoretical specific capacity of $585.6 \mathrm{~mA} \mathrm{~h} / \mathrm{g}$.

Open-circuit voltage (OCV) is another important parameter for evaluating the electrochemical properties of rechargeable batteries. OCV can be obtained by calculating the average voltage $\left(V_{\text {avg }}\right)$ within the range of $x_{1}<x<x_{2}$ in $\mathrm{Mg}_{x} \mathrm{FePS}_{3}$. $V_{\text {avg }}$ was calculated with the following expression:

$V_{\text {avg }}=-\frac{E\left(\mathrm{Mg}_{x_{2}} \mathrm{FePS}_{3}\right)-E\left(\mathrm{Mg}_{x_{1}} \mathrm{FePS}_{3}\right)-\left(x_{2}-x_{1}\right) E(\mathrm{Mg})}{2\left(x_{2}-x_{1}\right) \mathrm{e}}$
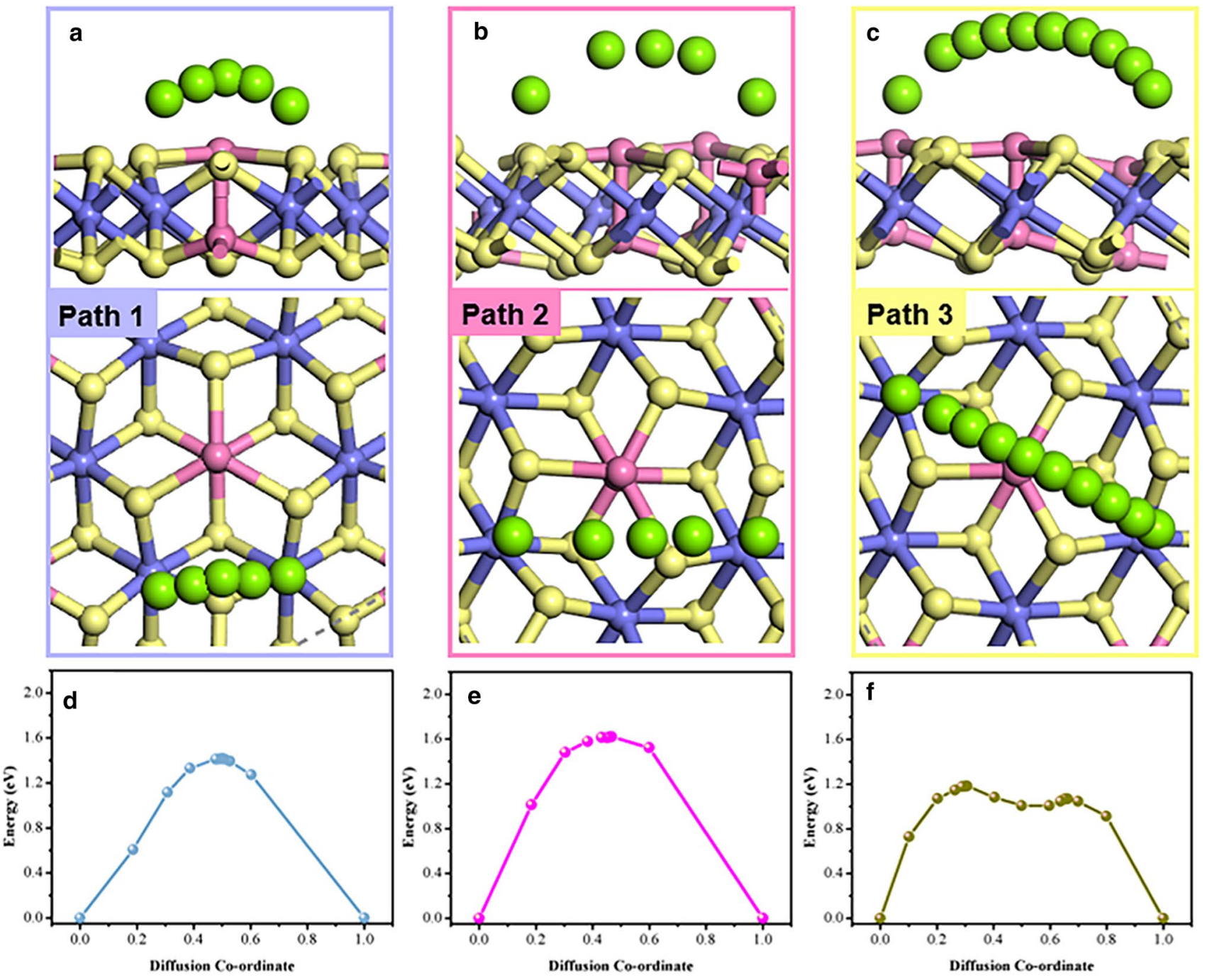

Fig. $3 \mathrm{Mg}$ diffusion on the surface of the $\mathrm{FePS}_{3}$ monolayer through paths $\mathbf{a} 1, \mathbf{b} 2$, and $\mathbf{c} 3$. Energy profiles of Mg diffusion through paths $\mathbf{d} 1$, e 2 , and $\mathbf{f} 3$ 

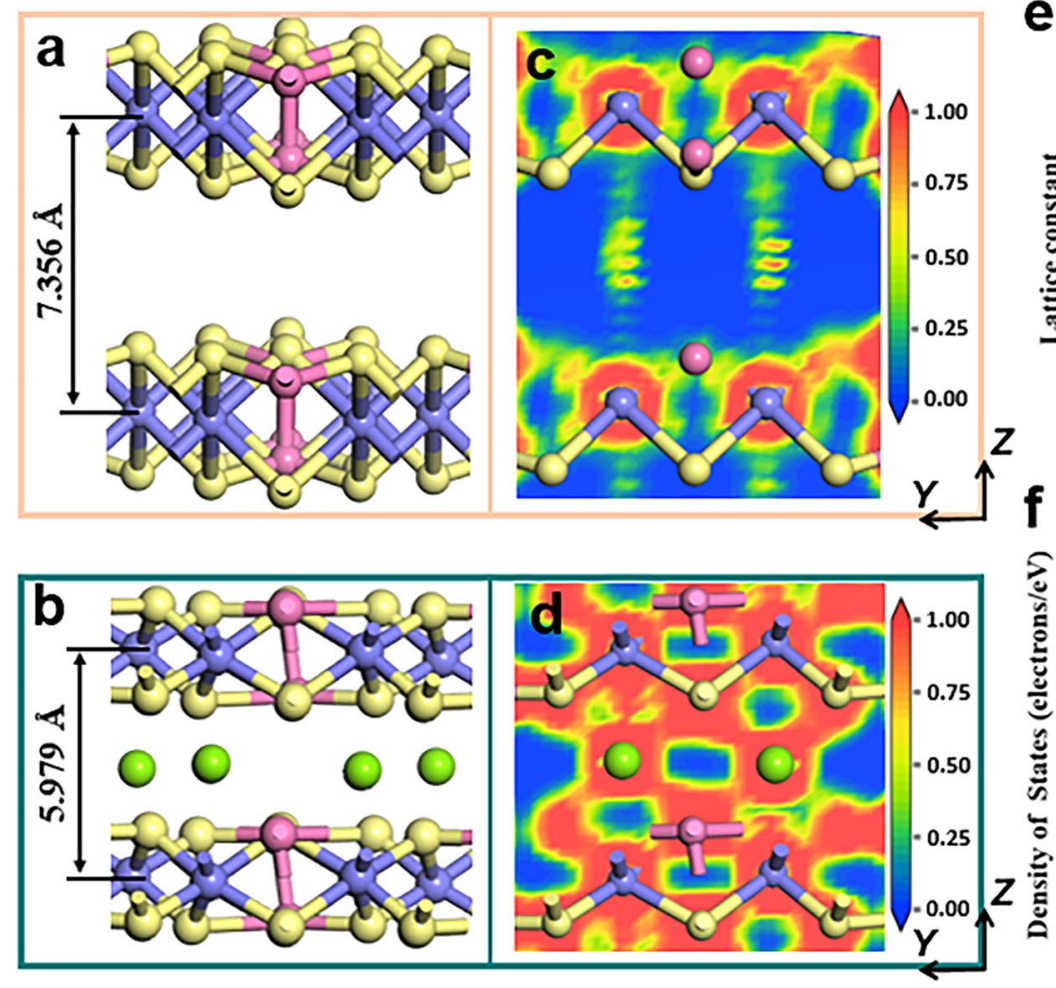
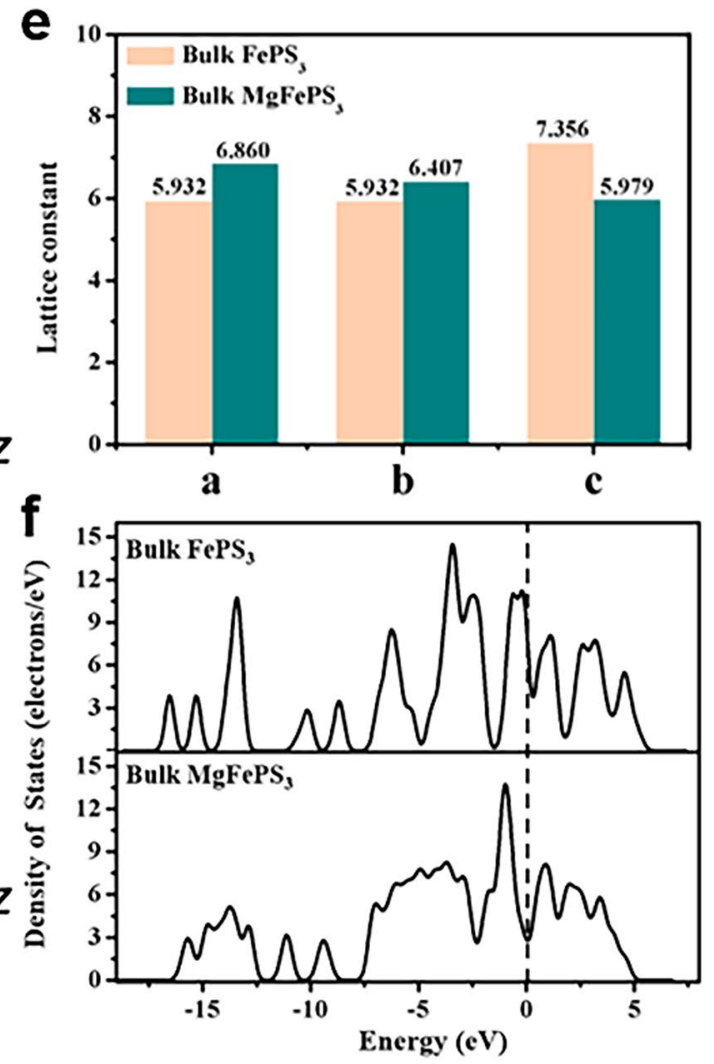

Fig. 4 Side structures of a bulk FePS 3 and b bulk $\mathrm{MgFePS}_{3}$; ELF slice maps of the c bulk FePS ${ }_{3}$ and $\mathbf{d}$ bulk MgFePS 3 ; e Lattice constants of bulk $\mathrm{FePS}_{3}$ and bulk $\mathrm{MgFePS}_{3}$; f Density of states (DOS) of bulk FePS 3 and bulk $\mathrm{MgFePS}_{3}$

behavior of $\mathrm{Mg}$ ion on the surface of an $\mathrm{FePS}_{3}$ monolayer should be understood. In this work, the linear synchronous transit/quadratic synchronous transit (LST/QST) method was used to evaluate the energy barriers of $\mathrm{Mg}$ ion diffusion through different paths. In Fig. 3a-c, three possible diffusion paths are found between two equilibrium $\mathrm{Fe}$ sites in the $\mathrm{FePS}_{3}$ monolayer. Path 1 is between the adjacent Fe sites (Fig. 3a), path 2 corresponds to adjacent secondary Fe sites (Fig. 3b), and path 3 connects the two Fe sites at the diagonal side of a hexagon (Fig. 3c). The calculated energy profiles of three diffusion paths are shown in Fig. 3d-f. Obviously, the results show that path 3 has a minimum energy barrier of $1.183 \mathrm{eV}$. The diffusion energy barriers of $\mathrm{Mg}$ ion along paths 1 and 2 are $1.426 \mathrm{eV}$ and $1.620 \mathrm{eV}$, respectively. Accordingly, $\mathrm{Mg}$ ion tends to migrate between the Fe sites at the diagonal side of the hexagon, and the relatively low energy barrier contributes to fast ionic diffusion and electrochemical reaction kinetics.

\section{Mg Storage Properties of Bulk FePS}

The $\mathrm{Mg}$ storage properties in bulk $\mathrm{FePS}_{3}$ were also tested. In Fig. 4a, bulk FePS 3 exhibits an A-A stacking model after structure relaxation. $\mathrm{Mg}$ was placed at the middle of the $\mathrm{Fe}$ sites at two consecutive layers in bulk $\mathrm{FePS}_{3}$ in consideration of the characteristics of $\mathrm{Mg}$ storage in the $\mathrm{FePS}_{3}$ monolayer. The maximum $\mathrm{Mg}$ storage capacity corresponds to the formula of $\mathrm{MgFePS}_{3}$ with a theoretical specific capacity of $292.8 \mathrm{~mA} \mathrm{~h} / \mathrm{g}$. The volumetric expansion of electrode materials causes the pulverization of electrodes and unstable SEI films. The change in volume was investigated on the basis of the changes in crystal cell parameters and interlamellar space in bulk FePS 3 . In Fig. 4a, the distance between two $\mathrm{Fe}$ atoms in the two adjacent layers in the original bulk $\mathrm{FePS}_{3}$ is $7.356 \AA$. After $\mathrm{Mg}$ insertion, the distance between the two Fe atoms decreases to $5.979 \AA$ (Fig. 4b), indicating the volume reduction in the $z$ axial direction. Lattice constant is also an important parameter to express the change in the volume of the bulk FePS 3 . The lattice constants $(1 \times 1$ cell) of $\mathrm{FePS}_{3}$ and $\mathrm{MgFePS}_{3}$ are summarized in Fig. 4e. In particular, the constants increase by $15.6 \%$ and $8.0 \%$ for $a$ and $b$, respectively, whereas the constant decreases by $18.7 \%$ for $c$. This finding is consistent with the decrease in the interlayer space. The lattice volume of bulk $\mathrm{FePS}_{3}$ changes from 215.48 to $206.70 \AA^{3}$ after $\mathrm{Mg}$ insertion, indicating that the volume of $\mathrm{FePS}_{3}$ has a little shrink but not expansion for magnesiation process. The small volumetric change is 
beneficial to the structural integrity of electrodes during the insertion/extraction of $\mathrm{Mg}$ ion.

Volume reduction mainly results from a decrease in the interlayer space in bulk $\mathrm{FePS}_{3}$. Electron localization function (ELF) slice maps (Fig. 4c, d) were used to explain the phenomenon of interlayer space reduction after $\mathrm{Mg}$ insertion. In Fig. 4c, almost no electrons are localized at the interlayer in bulk $\mathrm{FePS}_{3}$, illustrating that the interlayer interaction mainly belongs to van der Waals forces. When a $\mathrm{Mg}$ atom inserts into the interlayer of bulk $\mathrm{FePS}_{3}$, electrons tend to distribute between $\mathrm{Mg}$ atoms and $\mathrm{FePS}_{3}$ layers. The interlayer force becomes electrostatic interaction, which is stronger than van der Waals forces, leading to a reduction in the interlayer distance. The $\mathrm{Mg}$ diffusion behavior in the interlayer of bulk $\mathrm{FePS}_{3}$ was also calculated. In Fig. S2, unlike the Mg diffusion behavior on the surface of the $\mathrm{FePS}_{3}$ monolayer, $\mathrm{Mg}$ cannot diffuse along paths 2 and 3 but prefers to diffuse along path 1 during the transition state search process. Diffusion behavior differs possibly because the limited space between $\mathrm{FePS}_{3}$ layers restricts the diffusion of $\mathrm{Mg}$ ion at a long distance, such as paths 2 and 3. Therefore, $\mathrm{Mg}$ ion tends to migrate through path 1 with a short diffusion distance (Fig. S3), and the corresponding diffusion energy barrier is $1.557 \mathrm{eV}$. Another important parameter affecting the electrochemical performance of rechargeable batteries is the electronic conductivity of electrode materials. The electronic conductivities of bulk $\mathrm{FePS}_{3}$ and $\mathrm{MgFePS}_{3}$ were evaluated in terms of density of states (DOS). In Fig. 4f, the electronic state at a Fermi level is not zero for $\mathrm{FePS}_{3}$ and $\mathrm{MgFePS}_{3}$, indicating that they exhibit a metallic behavior. In Fig. S4, the band gap of bulk $\mathrm{MgFePS}_{3}(0.306 \mathrm{eV})$ is smaller than that of bulk $\mathrm{FePS}_{3}(0.550 \mathrm{eV})$, demonstrating that the insertion of $\mathrm{Mg}$ ion in the interlayer of bulk $\mathrm{FePS}_{3}$ can improve electronic conductivity.

\section{Conclusions}

In this work, DFT calculations were conducted to investigate various electrochemical properties of 2D layered $\mathrm{FePS}_{3}$ for $\mathrm{Mg}$ storage. $\mathrm{FePS}_{3}$ can be used as an anode material for $\mathrm{Mg}$ ion batteries because of the following advantages: (1) $\mathrm{Mg}$ can be loaded at Fe sites in FePS with a stable structure and high theoretical specific capacities of $585.6 \mathrm{~mA} \mathrm{~h} / \mathrm{g}$ for monolayers and $292.8 \mathrm{~mA} \mathrm{~h} / \mathrm{g}$ for bulk materials. (2) It can provide a relatively low voltage of $0.483 \mathrm{~V}$ (vs. $\mathrm{Mg} / \mathrm{Mg}^{2+}$ ), contributing a high power density in full batteries. (3) The volumetric change in $\mathrm{FePS}_{3}$ is only $4.0 \%$ for full $\mathrm{Mg}$ insertion, and both $\mathrm{FePS}_{3}$ and its reduction products of $\mathrm{MgFePS}_{3}$ exhibit good electronic conductivity, which are beneficial to cycling stability and high-rate performance, respectively.
Acknowledgements This work was supported by Tianjin Science and Technology Project (19YFSLQY00070), the National Natural Science Foundation of China (No. 21878216), the Opening Foundation of State Key Laboratory of Organic-Inorganic Composites, Beijing University of Chemical Technology (oic-201901004, oic-201801003).

Open Access This article is licensed under a Creative Commons Attribution 4.0 International License, which permits use, sharing, adaptation, distribution and reproduction in any medium or format, as long as you give appropriate credit to the original author(s) and the source, provide a link to the Creative Commons licence, and indicate if changes were made. The images or other third party material in this article are included in the article's Creative Commons licence, unless indicated otherwise in a credit line to the material. If material is not included in the article's Creative Commons licence and your intended use is not permitted by statutory regulation or exceeds the permitted use, you will need to obtain permission directly from the copyright holder. To view a copy of this licence, visit http://creativecommons.org/licenses/by/4.0/.

\section{References}

1. Dunn B, Kamath H, Tarascon JM (2011) Electrical energy storage for the grid: a battery of choices. Science 334(6058):928-935

2. Liu J, Zhang JG, Yang ZG et al (2013) Materials science and materials chemistry for large scale electrochemical energy storage: from transportation to electrical grid. Adv Funct Mater 23(8):929-946

3. Li H, Wang ZX, Chen LQ et al (2009) Research on advanced materials for Li-ion batteries. Adv Mater 21(45):4593-4607

4. Etacheri V, Marom R, Elazari R et al (2011) Challenges in the development of advanced Li-ion batteries: a review. Energy Environ Sci 4(9):3243

5. Liu C, Wang YH, Sun J et al (2020) A review on applications of layered phosphorus in energy storage. Trans Tianjin Univ 26(2):104-126

6. Li L, Lu Y, Zhang Q et al (2019) Recent progress on layered cathode materials for nonaqueous rechargeable magnesium batteries. Small. https://doi.org/10.1002/smll.201902767

7. Rashad M, Asif M, Wang YX et al (2020) Recent advances in electrolytes and cathode materials for magnesium and hybrid-ion batteries. Energy Storage Mater 25:342-375

8. Han XP, Liu C, Sun J et al (2018) Density functional theory calculations for evaluation of phosphorene as a potential anode material for magnesium batteries. RSC Adv 8(13):7196-7204

9. Wei LY, Lian RQ, Zhao YY et al (2020) Experimental investigation and first-principles calculations of a $\mathrm{Ni}_{3} \mathrm{Se}_{4}$ cathode material for Mg-ion batteries. ACS Appl Mater Interfaces 12(8):9316-9321

10. Asif M, Rashad M, Shah JH et al (2020) Surface modification of tin oxide through reduced graphene oxide as a highly efficient cathode material for magnesium-ion batteries. J Colloid Interface Sci 561:818-828

11. Kong L, Yan C, Huang JQ et al (2018) A review of advanced energy materials for magnesium-sulfur batteries. Energy Environ Mater 1(3):100-112

12. Li YQ, Zuo PJ, Li RN et al (2019) Electrochemically-driven interphase conditioning of magnesium electrode for magnesium sulfur batteries. J Energy Chem 37:215-219

13. Wu DH, Yang BC, Chen HY et al (2019) Mechanical deformation induced charge redistribution to promote the high performance of stretchable magnesium-ion batteries based on two-dimensional C2N anodes. Nanoscale 11(33):15472-15478 
14. Deng XW, Xu YN, An QY et al (2019) Manganese ion pre-intercalated hydrated vanadium oxide as a high-performance cathode for magnesium ion batteries. J Mater Chem A 7(17):10644-10650

15. Lancry E, Levi E, Gofer $Y$ et al (2004) Leaching chemistry and the performance of the $\mathrm{Mo}_{6} \mathrm{~S}_{8}$ cathodes in rechargeable $\mathrm{Mg}$ batteries. Chem Mater 16(14):2832-2838

16. Tao ZL, Xu LN, Gou XL et al (2004) $\mathrm{TiS}_{2}$ nanotubes as the cathode materials of Mg-ion batteries. Chem Commun 18:2080

17. Drosos C, Jia CL, Mathew S et al (2018) Aerosol-assisted chemical vapor deposition of $\mathrm{V}_{2} \mathrm{O}_{5}$ cathodes with high rate capabilities for magnesium-ion batteries. J Power Sour 384:355-359

18. Wang L, Welborn SS, Kumar H et al (2019) High-rate and long cycle-life alloy-type magnesium-ion battery anode enabled through (De) magnesiation-induced near-room-temperature solidliquid phase transformation. Adv Energy Mater 9(45):1902086

19. Yaghoobnejad Asl H, Fu JT, Kumar H et al (2018) In situ dealloying of bulk $\mathrm{Mg}_{2} \mathrm{Sn}$ in $\mathrm{Mg}$-ion half cell as an effective route to nanostructured $\mathrm{Sn}$ for high performance $\mathrm{Mg}$-ion battery anodes. Chem Mater 30(5):1815-1824

20. Kravchyk KV, Piveteau L, Caputo R et al (2018) Colloidal bismuth nanocrystals as a model anode material for rechargeable Mg-ion batteries: atomistic and mesoscale insights. ACS Nano 12(8):8297-8307

21. Lee J, Monserrat B, Seymour ID et al (2018) An ab initio investigation on the electronic structure, defect energetics, and magnesium kinetics in $\mathrm{Mg}_{3} \mathrm{Bi}_{2}$. J Mater Chem A 6(35):16983-16991

22. Huie MM, Bock DC, Takeuchi ES et al (2015) Cathode materials for magnesium and magnesium-ion based batteries. Coord Chem Rev 287:15-27

23. Julien C, Mauger A, Zaghib K et al (2016) Optimization of layered cathode materials for lithium-ion batteries. Materials 9(7):595

24. Deng YP, Wu ZG, Liang RL et al (2019) Layer-based heterostructured cathodes for lithium-ion and sodium-ion batteries. Adv Funct Mater 29(19): 1808522

25. Chen CC, Wang JB, Zhao Q et al (2016) Layered $\mathrm{Na}_{2} \mathrm{Ti}_{3} \mathrm{O}_{7} / \mathrm{MgNa}-$ $\mathrm{Ti}_{3} \mathrm{O}_{7} / \mathrm{Mg}_{0.5} \mathrm{NaTi}_{3} \mathrm{O}_{7}$ nanoribbons as high-performance anode of rechargeable Mg-ion batteries. ACS Energy Lett 1(6):1165-1172

26. Luo L, Zhen YC, Lu YZ et al (2020) Structural evolution from layered $\mathrm{Na}_{2} \mathrm{Ti}_{3} \mathrm{O}_{7}$ to $\mathrm{Na}_{2} \mathrm{Ti}_{6} \mathrm{O}_{13}$ nanowires enabling a highly reversible anode for Mg-ion batteries. Nanoscale 12(1):230-238

27. Ye XJ, Zhu GL, Liu J et al (2019) Monolayer, bilayer, and heterostructurearsenene as potential anode materials for magnesium-ion batteries: a first-principles study. J Phys Chem C 123(25):15777-15786

28. Zhang ZZ, Zhang YF, Li Y et al (2018) $\mathrm{MnSb}_{2} \mathrm{~S}_{4}$ monolayer as an anode material for metal-ion batteries. Chem Mater 30(10):3208-3214

29. Xie Y, Dall'Agnese Y, Naguib M et al (2014) Prediction and characterization of MXene nanosheet anodes for non-lithium-ion batteries. ACS Nano 8(9):9606-9615

30. Vakili-Nezhaad GR, Gujarathi AM, Al Rawahi N et al (2019) Performance of $\mathrm{WS}_{2}$ monolayers as a new family of anode materials for metal-ion $(\mathrm{Mg}, \mathrm{Al}$ and $\mathrm{Ca}$ ) batteries. Mater Chem Phys 230:114-121
31. Zhang JH, Liu G, Hu HC et al (2019) Graphene-like carbon-nitrogen materials as anode materials for Li-ion and $\mathrm{Mg}$-ion batteries. Appl Surf Sci 487:1026-1032

32. Chittari BL, Park Y, Lee D et al (2016) Electronic and magnetic properties of single-layer $\mathrm{MPX}_{3}$ metal phosphorous trichalcogenides. Phys Rev B 94(18):184428

33. Kargar F, Coleman EA, Ghosh S et al (2020) Phonon and thermal properties of quasi-two-dimensional $\mathrm{FePS}_{3}$ and $\mathrm{MnPS}_{3}$ antiferromagnetic semiconductors. ACS Nano 14(2):2424-2435

34. Brec R, Schleich DM, Ouvrard G et al (1979) Physical properties of lithium intercalation compounds of the layered transition-metal chalcogenophosphites. Inorg Chem 18(7):1814-1818

35. Wang M, Tang KB (2019) A facile synthesis of FePS 3 @ nanocomposites and their enhanced performance in lithium-ion batteries. Dalton Trans 48(12):3819-3824

36. Fujii Y, Miura A, Rosero-Navarro NC et al (2018) Reaction mechanism of $\mathrm{FePS}_{3}$ electrodes in all-solid-state lithium secondary batteries using sulfide-based solid electrolytes. J Electrochem Soc 165(13):A2948-A2954

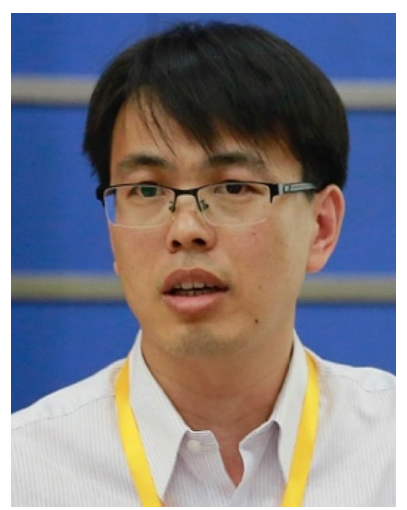

Zhanxu Yang is a professor and the director of College of Chemistry, Chemical Engineering and Environmental Engineering in Liaoning Shihua University. $\mathrm{He}$ received his Ph.D. from Beijing University of Chemical Technology in 2009. As Principal Investigator in the field of electrochemistry, he has actively led and participated in the research of energy storage materials, catalytic materials, and petroleum processing aids.

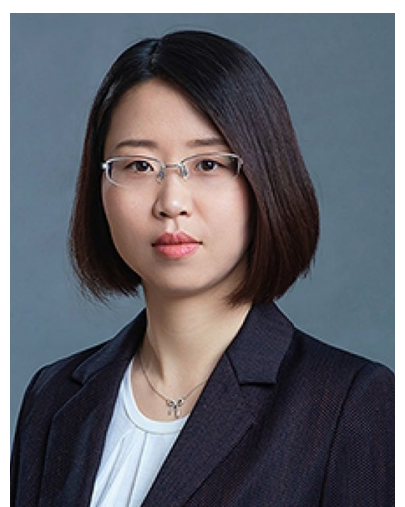

Jie Sun is a professor at the Tianjin University, China. She earned her Ph.D. from the Beijing University of Chemical Technology and then worked as a postdoctoral at the Stanford University. Her current research interests focus on the development of multifunctional nanomaterials for energy conversion and storage, including Li-ion, Na-ion, $\mathrm{K}$-ion, and $\mathrm{Mg}$-ion batteries, lithium-sulfur batteries, as well as electrocatalysis. 